\title{
Nonverbal Communication in Pride and Prejudice
}

\author{
Lili Zhan \\ Department of Foreign Languages, Dalian University of Technology, Dalian, China \\ Email: zhan7939@yahoo.com.cn
}

\begin{abstract}
Language has been the focus of traditional studies on communication. However, real communication does not merely include verbal codes. Nonverbal forms, in fact, send an enormous number of messages in communication, or sometimes, even carry a larger flow of information than verbal codes. This paper, through analyzing nonverbal communication in Pride and Prejudice, is intended to show the roles played by nonverbal forms in literary works: how they operate with verbal codes, how they reveal the characters' emotions, how they can exhibit social customs, and how they represent the characters' social status, and in the meanwhile to discuss how nonverbal communication helps develop the plot, mold the characters and reveal the theme of the novel.
\end{abstract}

Index Terms - nonverbal, Pride and Prejudice, emotion, status, social customs

\section{INTRODUCTION}

When we talk about means of communication, language perhaps is the first which occurs to us. Here, language is referred to as a sign of a combination of sound and meaning. The general trend of communication studies has largely been focused on language. But in fact, communicative means does not just involve verbal channel, it also encompasses varieties of nonverbal forms. Nonverbal, as the term suggests, does not involve any use of words or speech. Eisenberg and Smith (1971) note that "nonverbal communication refers to all communication except that which is coded in words" (p. 20). Levine and Adelman (1982) point out that "in some types of communication people express more nonverbally than verbally" (p. 43). Birdwhistell (1961) holds that information carried by verbal forms during an interaction accounts for no more than $30 \%$ while the rest is all sent through nonverbal means. The importance of nonverbal communication can also be seen in the division of communicative language ability into language competence and strategic competence in sociological study, among which strategic competence refers to mastery of nonverbal as well as verbal forms.

However, in reality, nonverbal and verbal communications are inseparably interconnected. Basically, almost all the verbal communication will more or less involve some nonverbal cues: illocutors' eye movement, smile or hand gestures all send messages from time to time. Nonverbal cues can act upon the verbal expressions. For example, a person who keeps looking around when giving his explanation for being late may be considered as being lying. However, a single nonverbal form alone may not impart a clear and definite message without the help of verbal remarks. For example, a mother may feel worried and at a loss if her daughter comes back home with tears but refusing to say anything. This paper, with the expectation of raising the awareness of nonverbal means, will first compare verbal and nonverbal communications, then present classifications of nonverbal forms, and at last illustrate the roles of nonverbal forms with examples taken from Pride and Prejudice.

\section{Verbal AND NONVERBAL COMMUNICATION SYSTEMS}

Language is an object which has been studied thoroughly and is closely related to nonverbal codes. So a comparison between verbal and nonverbal systems can help obtain a deeper understanding of the nature of nonverbal communication. The comparison will be developed in light of arbitrariness, grammaticality, self-reflexivity and sense organs involved.

First, language is arbitrary in the sense that there is no logical connection between meaning and sound. Although nonverbal symbols, like the linguistic forms, are arbitrarily chosen, yet they are usually linked to the intended message. For example, the way of pointing is arbitrary: some cultures point with their entire head, some cultures point with their lips while people in some cultures point with their fingers. Despite the differences in form, the direction designated can always be deduced from the direction in which different nonverbal forms indicate. Thus, the act of pointing is not arbitrary. Language is tightly organized. Individual words can be constructed into a well-formed sentence according to certain grammatical rules. However, no clear demonstration shows that nonverbal codes can be combined in the same way. Self-reflexivity of verbal expressions refers to the fact that language can be used to talk about language itself. That's what this paper is doing now. But nonverbal codes are unlikely to be used to analyze nonverbal communication. The behavior nodding is unlikely to explain how nodding is produced or comprehended. Lastly, nonverbal cues are received by different sense organs at the same time for a person can feel, smell, see and hear messages at the same time. 
Verbal communication, however, involves far fewer types of sense receptors. One either sees written language or hears oral messages. Consequently one is more likely to receive different messages sent through nonverbal channels than to receive and comprehend two verbal messages simultaneously.

\section{ClassificAtions OF NONVERBAL COMMUNiCATION}

Various classifications of nonverbal behaviors have been proposed. Scollon, R. and Scollon, S. (2000) note that nonverbal communication "would include our posture, our movements, our attire, our use of space, and our use of time" (p. 143). They focus their intercultural studies of nonverbal communication on three aspects: "the movements of our bodies (called kinesics), our use of space (called proxemics), and our use of time" (p. 143) because they believe that these three aspects are directly relevant to intercultural communication. Levine and Adelman (1982) who are also engaged in intercultural communication include gestures, facial expressions, eye contact, and space within their discussions of nonverbal communication (p. 44-47).

Knapp and Hall (2002) make a more detailed classification of nonverbal behaviors (p.7-10). They first categorize nonverbal communication into "three primary units: the environment structures and conditions within which communication takes place, the physical characteristics of the communicators themselves, and the various behaviors manifested by the communicators" (Knapp \& Hall, 2002, p.7), and then a detailed breakdown of the three features has been provided. The communication environment is broken down into physical environment, including "furniture, architectural style, interior decorating, lighting conditions, colors, temperature, additional noises or music, and the like" (Knapp \& Hall, 2002, p.7), and spatial environment which mainly focuses on proxemics. The communicators' physical characteristics cover such things like physique or body shape, height, hair, and artifacts which may affect their physical appearance, such as jewelry, lipstick, clothes. Body movement and position is further divided into gestures, postures, touching behavior, facial expressions, eye behavior, and vocal behavior. Condon and Yousef (1975) summarize 24 kinds of nonverbal forms; however, they point out that it is impossible and unnecessary to make an exhaustive list of all the nonverbal means. Chinese scholar Bi Jiwan (1996), after sorting out and integrating different scholars' categorizations, puts forward his classifications of nonverbal communication which are taken as frame of reference in this paper since he incorporates other researchers' major categorizations within his classificatory system and presents comprehensive classifications of nonverbal communication. Bi classifies nonverbal forms into four categories, each of which includes some sub-categories. A brief description of Bi's classification system is presented below.

1) Body language. Body language includes movement of the whole body or certain parts of the body. Posture, head gesture, facial expression, eye movement, hand gesture and touching behavior fit into this category.

2) Paralanguage. Paralanguage embraces silence, turn-taking, and vocal nonverbal sounds such as pitch, volume, intonation of the speech, etc.

3) Object language. Object language refers to those material things which have the effect of expressing some features about the displayer. Clothes, furniture, personal artifacts can all be used as objects for expressive display.

4) Environmental language. Environment is part of nonverbal communication, too. It includes space (crowdedness, proxemics, territoriality, seating arrangement), time, architectural arrangement and interior decoration, lighting, color, and signs.

\section{Nonverbal Communication in PRide and PREJUdice}

Nonverbal codes do not merely occur in daily conversations. Literary writers also make enormous descriptions of nonverbal communication in their works. In this paper, Jane Austen's novel Pride and Prejudice is taken as an example to illustrate the roles played by nonverbal forms and explain in the meanwhile how they contribute to plot-developing, characters-shaping and theme-revealing.

\section{A. Operating with Verbal Expressions}

As is mentioned previously, nonverbal cues usually appear together with verbal symbols. The meaning of each communication is to be found and understood by incorporating both nonverbal and verbal forms. Just as Knapp and Hall (2002) have noted, "because verbal and nonverbal systems operate together as part of the larger communication process, efforts to distinguish clearly between the two have not been successful" (p. 11). Ekman (1965) (cited in Knapp \& Hall, 2002, p.12) summarizes the following roles that nonverbal forms play in interrelating with verbal behaviors: "repeating, contradicting, complementing, substituting, accenting/moderating, and regulating". The following part is going to explain some of the functions with examples from Pride and Prejudice.

1. Complementing verbal expressions

Nonverbal cues can help clarify verbal messages. At the first ball in Herfordshire, Darcy said to Mr. Bingley:

(1) "You're dancing with the only handsome girl in the room," said Mr. Darcy, looking at the eldest Miss Bennet.

(Austen, 1983, p.9)

The direction in which Darcy casts his eye shows who he is referring to as the only handsome girl. Though the referent can be inferred from the later plot development even without the nonverbal cue, the eye movement undoubtedly helps shorten the inferring process and clarify the verbal message. 
The supplementary function of nonverbal cues can also been seen in their description of verbal expressions. The scene in the following excerpt happens after Mr. Bingley suggests introducing Elizabeth to his friend Darcy. Darcy's sequence of nonverbal behaviors modify his verbal remarks and display his attitude towards Elizabeth.

(2) "Which do you mean?" and turning around, he looked for a moment at Elizabeth, till catching her eye, he withdrew his own and coldly said, "She is tolerable; but not handsome enough to tempt me..."

(Austen, 1983, p.9)

This is the first time that Elizabeth and Darcy meet each other face to face. Nonverbal behaviors in this excerpt involve body movement (turning around), eye movement (looked, catching her eye, withdrew his own), time message (for a moment), and the tone (coldly). Usually it's impolite for a person to stare undisguisedly at another person that s/he meets for the first time; however, Darcy does that. Another socially unacceptable behavior is that Darcy keeps staring at Elizabeth and does not stop looking at her until she looks back. Tone falls into the category of paralanguage. "Coldly" describes the tone in which Darcy speaks, and with that, Darcy's arrogance has been pictured. In this except, Darcy's nonverbal behaviors along with his verbal remark "She is tolerable; but not handsome enough to tempt me..." depict Darcy's haughty image and also plant seeds of prejudice against Darcy in Elizabeth. The above analysis shows that nonverbal forms help reflect the theme of the novel: pride and prejudice.

2. Substituting verbal expressions

The supreme power of nonverbal forms is manifested in its substitution for verbal phrases. In most cases, it is the context that requires use of nonverbal codes to replace verbal expressions. For example:

(3) The next variation which their visit afforded was produced by the entrance of servants with cold meat, cake and a variety of all the finest fruits in season, but this did not take place till after many a significant look and smile from Mrs. Annesley to Miss Darcy had been given to remind her of her post.

(Austen, 1983, p.236)

A group of lady visitors, Miss Bingley, her married sister Mrs. Hurst, Elizabeth, her aunt Mrs. Gardiner, have paid their visit to Darcy's place, Pemberley. According to the social custom, Darcy's younger sister, Miss Darcy, is supposed to show hospitality as a hostess. However, because of her being shy, timid, and socially inexperienced, Miss Darcy has forgotten to ask the servant to bring things to entertain the visitors. Mrs. Annesley, the butler, certainly cannot engage her master into actions even with a friendly reminder because servants are not supposed to ask their master to do things. Besides, the immediate local context, in which guests have already been seated and not many conversations are being carried out, does not allow Mrs. Annesley to deliver a verbal reminder. If Mrs. Annesley said something to Miss Darcy, attention would be directed to the talking parties. Hence, it seems that anything in the verbal form may cause embarrassment for Miss Darcy. Under such circumstances, the imperceptible nonverbal forms are just perfect to serve Mrs. Annesley's purpose and keep Miss Darcy's dignity.

3. Contradicting verbal expressions

More commonly words and actions are in harmony, but sometimes words do not correspond to behaviors. In such cases, nonverbal behaviors are considered more reliable because most of them are performed subconsciously and less controllable. So they are more likely to reveal one's genuine intentions and feelings. For example:

(4) Miss Bingley moved with alacrity to the piano-forte, and after a polite request that Elizabeth would lead the way, which the other as politely and more earnestly negatived, she seated herself.

(Austen, 1983, p.44)

Miss Bingley has been longing to be Mrs. Darcy. So when Darcy asks for some music, Miss Bingley is too impatient to wait and moves to the piano before Elizabeth has a chance to. Though she still pretends to be polite to ask Elizabeth to come first, her action (moved with alacrity, seated herself) has already exposed her real intention. Thus, her words are incredible. Besides, the contradiction between Bingley's words and her action reveals her character: hypocrisy and contempt.

\section{B. Revealing Emotional State}

Miller (1984) claims that only $7 \%$ of feelings and attitudes are conveyed by words while nearly $93 \%$ are done through nonverbal means. Eisenberg and Smith (1971) also admit that nonverbal communication is better suited for the projection of emotional states.

(5) He observed to her, at a moment when the others were talking together, and in a tone which had something of real regret, that "it was a very long time since he had had the pleasure of seeing her;" and before she could reply, he added, "It is above eight months. We have not met since the 26th of November when we were all dancing together at Netherfield."

(Austen, 1983, p.231)

The talk occurs between Mr. Bingley and Elizabeth. Bingley has not seen Miss Bennet since he left Hertfordshire, and he is trying to tell Elizabeth how much he misses her sister, Miss Bennet. The occasion (at a moment when the others were talking together) exhibits that the talk is private. The tone in which Bingley speaks (in a tone which had something of real regret) shows that Miss Bennet has occupied a special place in his heart. According to Hall (1973), time and space can talk and they speak more plainly than words. The descriptions of time "a very long time", "above eight months", "26th of November" and place "Netherfield" serve as eloquent evidences that Bingley has remembered clearly every detail related to Miss Bennet and he has cherished deep and enduring love towards her. 
Literary writers are good at keeping the message from readers and creating suspense in them. As is known, one's inner state and emotions are not easy to describe. The writer sometimes will choose to describe the characters' nonverbal behaviors and let readers themselves speculate about the characters' inside world. The role of nonverbal communication in disclosing emotional state and in creating suspense in Pride and Prejudice can never be illustrated more eloquently than the description of the accidental encounter between Wickham and Darcy.

(6) Elizabeth happened to see the countenance of both as they looked at each other, was all astonishment at the effect of the meeting. Both changed color, one looked white; the other red.

(Austen, 1983, p.64)

Wickman's father used to take care of Darcy's father's property, and they were on very good terms with each other. Darcy's father took Wickman as his godson and supported him all the way through college hoping him to become a clergyman. However, after Darcy's father died, Wickman immediately stopped all the work in church and lived a life of idleness and dissipation. When being refused to get further financial support from Darcy, Wickman devised a scheme to win Darcy's fifteen-year-old sister Georgiana's heart and even lured her into elopement. Fortunately, Georgiana acknowledged the whole to Darcy and avoided the misfortune.

Given subtle relationship between them, Wickham and Darcy are unlikely to talk to each other and must have had mixed feelings towards their unexpected meeting. Austen does not make many descriptions about their meeting; instead she just portrays their facial expressions to let readers themselves make speculations. Knapp and Hall (2002) note: "Most studies of the face are concerned with the configurations that display various emotional states. The six primary effects receiving the most study are anger, sadness, surprise, happiness, fear, and disgust" (p. 10). Readers, at this point, haven't been told what has happened between Wickham and Darcy, so they must be very eager to find out. Right after this excerpt, Austen interacts with her readers by saying: "What could be the meaning of it? — It was impossible to imagine; it was impossible not to long to know" (Austen, 1983, p.64). This scene proves to be one of the crises (the point during the plot when the action reaches its turning point) in Pride and Prejudice. Important events ensue from this crisis: Elizabeth's curiosity about what could have happened between Wickham and Darcy has brought herself into contact with Wickham; Wickman's distorted messages about Darcy intensify Elizabeth's prejudice against him; Elizabeth's sister, Lydia elopes with Wickham; Darcy delivers a letter to clarify what has happened between him and Wickham.

\section{Displaying Social Customs}

Like language, nonverbal forms are acquired in a particular culture. Therefore, they can reveal social customs as well. But nonverbal cues are more evident and direct than verbal codes in showing social customs in that they can be perceived directly with one's sense receptors.

(7) "... and so I let down the side glass next to him, and took off my glove, and let my hand just rest up the window frame, so that he might see the ring..."

(Austen, 1983, p.279)

It's a custom in western countries that married people usually wear a ring on the ring finger. Lydia on her way home makes use of this custom to show off to Mr. Goulding. The "ring" which belongs to artifacts is speaking in a silent way here, that is, being married.

(8) She then joined them soon enough to see Lydia, with anxious parade, walk up to her mother's right hand, and hear her say to her eldest sister, "Ah! Jane, I take your place now..."

(Austen, 1983, p.280)

In Britain, right-hand place symbolizes higher position. Usually, seating arrangements were made according to age. But once marriage intervened, age had to yield. Jane is the eldest in her family, so according to age ranking, she certainly has the privilege to sit to her mother's right hand. However, after Lydia has got married, Jane has to go lower and Lydia takes her place to sit to Mrs. Bennet's right hand. That's why Lydia says “Jane, I take your place now...”.

\section{Marking Social Identities}

Sometimes, even if we don't initiate a conversation with a stranger, we may still obtain some information about him/her through the nonverbal cues, such as clothes, accessories, and mannerism. Britain is known as a hierarchical society in which distinction between different social classes is clearly marked. People of noble origin labeled their status as apparently as possible. Emblems, attire and home decoration are all used to display their power and dignity. Carriage was a major means of transportation in Britain in the $18^{\text {th }}$ and $19^{\text {th }}$ centuries which Pride and Prejudice depicts and when Jane Austen lived. The carriage did not only function as a major transport carrier, but could tell the user's social status and identity as well just like today's car. According to Bi's classification (1999), carriages fall into the category of object language. The following examples are going to show how the carriage as a nonverbal code conveys information.

At the ball in Hertfordshire, Darcy's arrogance towards Mrs. Long is assigned as the following by Mrs. Benet:

(9) "... and I dare say he had heard somehow that Mrs. Long does not keep a carriage and had come to the ball in a hack chaise. $"$

(Austen, 1983, p.15)

As is mentioned above, carriage was considered as kind of status marker; therefore, those without a carriage were generally considered both economically and socially underprivileged. Mrs. Long does not have a carriage herself, so she 
has to hire a carriage, which only turns out to be a hack chaise - a carriage pulled by old and tired horses.

(10) ... when the sound of a carriage drew them to the window, and they saw a gentleman and lady in a curricle, driving up the street. Elizabeth immediately recognizing the livery, guessed what it meant....

(Austen, 1983, p.202)

Curricle refers to a light two-wheeled carriage usually drawn by two horses abreast. In the $18^{\text {th }}$ and $19^{\text {th }}$ centuries the livery, a special uniform worn by servants, designated which family the carriage belonged to. That's why Elizabeth can conclude that the visiting gentleman and the lady may be Mr. Darcy and Miss Darcy.

When the carriage of Mrs. Jenkinson, the butler, and Miss De Bourge stops in front of Mr. Collins' house:

(11) Maria ran upstairs to tell Elizabeth that there is a sight to be seen. "It was two ladies stopping in a low phaeton at the garden gate."

(Austen, 1983, p.141)

The phaeton is a light open four-wheeled carriage pulled by two horses. It was mainly used by the upper class but it was not commonly seen in the eighteenth century any more. So it is assumed that the phaeton is possessed by people of noble origin and is handed down from the older generation. The family name "De Bourge" verifies this conjecture because "De" is only used by those of "blue blood."

(12) Their attention was suddenly drawn to the window by the sound of a carriage; and they perceived a chaise and four driving up the lawn.

(Austen, 1983, p.311)

This excerpt describes Lady Catherine's coming to the Bennets. After she has got to know that her nephew Darcy, who was expected to marry her own daughter, is going to marry Elizabeth, she goes to talk to Elizabeth in person with bad grace. A chaise and four means that the carriage is drawn by four horses. And the number of horses shows that the coming visitors must be of wealth and high social position.

The foregoing discussion shows that a carriage can represent one's wealth and social status and people of different classes also choose a carriage which conforms to their identity. The examples (9)-(12) have shown that social status is largely proportional to the number of wheels and horses a carriage has, that is, the more horses and wheels there are, the higher one's status is.

Turn-taking, as part of nonverbal communication, is usually clearly marked during conversations. For example, slowing down the speech may suggest that the speaker is going to finish his/her part and ready to yield the turn whereas speeding up the speech may indicate that the speaker intends to hold the turn. Normally conversations consist of two or more participants taking turns. A current speaker usually makes pauses for others to pick up the turn. The basic pattern of talk is "I speak - you speak - I speak - you speak" (Yule, 2000, p.71). If a speaker violates this basic pattern, additional information will be imparted. For example:

(13) When the ladies returned to the drawing room, there was little to be done but to hear Lady Catherine talk, which she did without any intermission till coffee came in.

(Austen, 1983, p.146)

In this example, Lady Catherine does not obey the basic pattern of talk exchange. She speaks "without any intermission"; in other words, she monopolizes the whole talk and deprives others of chances to speak. This shows that Lady Catherine acts in a haughty, pompous, and domineering manner totally relying on her social status.

\section{CONCLUSION}

To study communication is to examine all the ways in which human beings send information and integrate their actions and feelings, in other words, is to study both verbal and nonverbal communications. However, the traditional study of communication has been mainly concentrating on verbal aspects. In fact, nonverbal forms play a very important role not only in face-to-face interaction but also in literary works. Taking Pride and Prejudice as an example, this paper illustrates how nonverbal communication helps convey verbal messages and makes contributions in revealing characters' feelings, marking their social status, and exhibiting social customs.

\section{REFERENCES}

[1] Austen, J. (1983). Pride and prejudice. London: Oxford University Press.

[2] Birdwhistell, R. L. (1961). Paralanguage: 25 years after Sapir. In H. W. Brosin (Ed.), Lectures in experimental psychiatry. Pittsburgh: University of Pittsburgh Press, 43-64.

[3] Eisenberg, A. M. \& R.R. Smith. (1971). Nonverbal communication. New York: The Bobbs-Merrill Company, Inc.

[4] Hall, E.T. (1973). The silent language. New York: Anchor Press.

[5] Knapp, M. L. \& J. A. Hall. (2002). Nonverbal communication in human interaction (5th edn.). Wadsworth: Thomson Learning, Inc.

[6] Levine, D. R. \& M. B. Adelman. (1982). Beyond language: Intercultural communication for English as a second language. Englewood Cliffs, N. J.: Prentice-Hall, Inc.

[7] Miller, P. (1984). Nonverbal communication. Washington: National Education Association.

[8] Scollon, R. \& S. W. Scollon. (2000). Intercultural communication: A discourse approach. Beijing: Foreign Language Teaching and Research Press.

[9] Yule, G. (2000). Pragmatics. London: Oxford University Press. 
Lili Zhan was born in Linkou, Hei Longjiang Province, China in 1979. She received her Master Degree in linguistics from Northeast Normal University, China in 2003.

She is currently a lecturer in the Department of Foreign Languages, Dalian University of Technology, China. Her research interests include discourse analysis and second language research. 